\title{
GLOSARIOS DE LAS LENGUAS DEL PACÍFICO ANTONIO PIGAFETTA (1519-1522)
}

1. El italiano Antonio Pigafetta (1480?-?) ha pasado a la posterioridad como el cronista de la expedición de Magallanes, el capitán portugués al mando de la flota de la corona de Castilla que entre 1519 y 1522 dio por vez primera la vuelta al mundo una vez encontrada una vía rápida con el Pacífico a través de la Tierra de Fuego.

Al margen del innegable valor histórico que reviste para el lector moderno la narración autobiográfica de Pigafetta, redactada en 1525 y entregada aquel mismo año en Valladolid al monarca Carlos I, la crónica de este miembro de la nobleza de Vicenza se caracteriza por incorporar en el cuerpo del relato cuatro glosarios que constituyen un rudimentario diccionario, con sus equivalentes italianos, de palabras y expresiones de las tribus del cono sur americano y de las islas del Pacífico que los expedicionarios encontraban a su paso.

En estas páginas estudiaremos tan sólo las entradas italianas', fjándonos en la selección léxica efectuada por el cronista. Ello nos permitirá pulsar la creciente curiosidad lingüística de Pigafetta a lo largo de los tres años de dura navegación.

2. Carecemos del diario de a bordo original en el que Pigafetta registraba las etapas del viaje, así como del arquetipo que hay que suponer escrito en italiano. De este arquetipo ha llegado hasta nosotros una copia manuscrita fechada hacia 1523 (Ms. Ambrosiano L. 103 Sup., Milán), que ha servido de base para una correcta edición moderna ${ }^{2}$.

Existen además tres copias francesas contemporáneas al manuscrito de Milán, una de las cuales (Ms. Français 5650, París), se utilizó como base de la primera impresión conocida: Le voyage et navigation faict par les Espaignolz es isles Molluques (París: s.f., pero entre 1526-36), edición muy abreviada respecto al manuscrito fuente. De esta edición francesa deriva la primera italiana: $l l$ viaggio fatto da gli Spagniuoli a tomo a'l mondo (Venecia: 1536). En definitiva, una retraducción al italiano a través del francés plagada de errores favorecidos por la compleja transmisión textual. El texto italiano que procedía de la traducción francesa fue recogido con todos sus defectos y otros nuevos en las Navigazionie

1 El vocabulario indígena ha sido en parte estudiado por D. Briton, Studies in South American Native Languages, Filadelía, 1892.

2 Antonio Pigafetta, Il primo viaggio intorno al mondo, ed. Camillo Manfroni, Milano, 1956. En lo sucesivo VM. 
Viaggi (Venecia:1536) de Giovanni Battista Ramusio, magna recopilación que en su momento divulgó las expediciones clásicas y los más recientes descubrimientos geográficos.

El texto transmitido por Ramusio ${ }^{3}$ presta mucha menor atención al factor lingüístico tan revelador del talante de Pigafetta. Además de recoger tan sólo una pequeña muestra de los inventarios léxicos, Ramusio los transmite con un gran descuido ortográfico. De ahí la necesidad de tener VM como base de nuestro trabajo, no sólo porque el manuscrito utilizado está más cerca del arquetipo, sino también por haberse conservado en la lengua de la redacción original evitando de ese modo la corrupción del texto a causa de la traducción francesa y de la posterior retraducción italiana.

3. Las palabras de las tribus de Verzin (actual territorio brasileño, y primera etapa de los expedicionarios) recopiladas por Pigafetta son sólo ocho. El contacto prolongado con los indios Patagones le proporciona ya un inventario de 90 entradas. El tercer inventario incluido en la relación es fruto de la estancia en el archipiélago filipino y consta de 159 voces, a las que hay que añadir otras diseminadas en el cuerpo del relato. Es ésta la primera ocasión en la que el expedicionario italiano se deja llevar por el reclamo lingüístico, como contagiado por la habilidad comunicativa de los habitantes de estas islas. Pigafetta no vacila en establecer contacto directo con los nativos, a los que sin necesidad de intérprete (VM90 sempre parlando con segni), interroga para transcribir de ese modo sus palabras sobre el papel, causando asombro entre aquellas poblaciones que no conocen aún la escritura ${ }^{4}$.

El inventario léxico cuantitativamente más importante (409 voces, entre palabras y frases de sentido completo), es el recopilado por Pigafetta en las islas Molucas. En conjunto refleja una mayor integración del occidental en la comunidad de estas islas, así como una conciencia lingüística mucho más acentuada en esta parte final de] viaje. Hay también una necesidad de aprendizaje mucho más acuciante, sobre todo después de que el intérprete Enrique de Malaca ha abandonado a los navegantes a la muerte de Magallanes, recobrando de ese modo su libertad. ${ }^{5}$

Viaggio di Antonio Pigafetta, en G.B. Ramusio, Navigazioni e Viaggi. Vol. 2, ed. Marica Milanesi, Torino, 1978, pp. 869-948.

$4 \quad$ En VM 91 "Scrissi assai cose come le chiamavano. Quando lo re e li altri me visteno scrivere ell diceva quelle sue parole, tutti restomo attonit"

5 No nos detendremos por extenso en la técnica de reciutamiento de interpretes por parte de las expediciones al Nuevo Mundo, aspecto para el que la crónica de Pigafetta constituye un clocumento de excepción (cf. VM 69 y 88). El intérprete, del que nos llega incluso su nonbbre, Enrique de Malaca, goza en todo momento de un gran protagonismo: antes de que Magallanes salte a tierra es el quien primero se entrevista con los caciques del Pacífico, con los que en determinadas ocasiones llega a comportarse con total autonomía, con una conciencia absoluta de ser el único vínculo con aquel mundo desconocido a los occidentales. Así en VM 97, cuando dando a entender el je fede la tribu que los recién llegados tendrán que pagar tributo por haber atracado en la ensenada, el intérprete toma la iniciativa sin necesidad de consultarse con el capitán general: Lo interprete li disse como el suo signore, per essere capitano de tanto gran re, non pagava tributo ad alcuno signore del mondo (...) e, se non voleva esserli amico, li mandaria un'altra fiata tanta gente che lo destrueriano. La libertad de acción del intérprete Enrique de Malaca tiene su contrapartida. Un esclavo con una conciencia tan clara de la importancia de su función para el grupo de expedicionarios, llegado el momento sabrá sacar partido de su imprescindibilidad: cuando Magallanes muera, Enrique acabará confraternizando con los indígenas y traicionando a los navegantes (VM 115 y s.). Poco a poco surge pues la necesidad de que sea el propio viajero occidental quien pueda establecer contacto personal mediante la adquisición de un múnimo vocabulario en las distintas lenguas. 
4.1. Un grupo semántico común a los cuatro glosarios es el constituido por todos aquellos objetos de trueque que los expedicionarios solían intercambiar con las tribus indígenas a cambio de comida, de especias o de metales preciados. Son por lo general herramientas de hierro o de otros materiales (latón'y porcelana) desconocidos en aquellas latitudes: anzuelos, cuchillos, tijeras, agujas de coser, peines, cascabeles. Objetos todos ellos de estricta funcionalidad que sin duda serían abundantes en las cubiertas de los galeones.

4.2. Las exigencias de la navegación le induce a incluir el léxico referido a elementos de la naturaleza y accidentes geográficos (el mar, el río, la tierra firme, la montaña, la isla); las fracciones temporales (el año, el mes, el día, la noche, la tarde, el mediodía, la madrugada); así como el registro de los vientos más importantes (levante, poniente, gregal, garbino, mistral, siroco).

4.3. Con excepción de los vocablos recopilados en Verzin, tampoco falta en ninguno de los inventarios la enumeración de las partes del cuerpo humano en la que el aspecto funcional del lenguaje pasa a un segundo plano, y que constituye para Pigafetta el punto de partida más inmediato para establecer comunicación con los indígenas.

4.4. Las denominaciones de los frutos de la tierra, que tan poderosamente llamaron la atención de los primeros expedicionarios a América, ocupan en los glosarios de Pigafetta un espacio importante. El maíz, las patatas y la piña son los que registra a su paso por Verzin. De menor relevancia es este apartado cuando los viajeros se detienen en la Patagonia, latitud extrema poco propicia al cultivo. Pigafetta registra allí lacónicamente: Alla polvere d'erba che mangiano = 'capac'.

En Filipinas, junto a frutos conocidos ya en occidente (como la naranja, el coco, el arroz, la miel, el higo), le salen al encuentro otros para los que no encuentra equivalente: tube = canne dolci, la areca, fruto de Limasawa, y el vino de palma o vraca. El paso por el archipiélago filipino le brinda además la primera ocasión para registrar los nombres originales de las especias que desde mucho antes habían llegado a Europa por la ruta de Asia: la pimienta, el clavo, el jenjibre y la canela.

4.5. Asimismo se registra escrupulosamente la fauna exótica: anta en Verzin; hoihoi = struzo uccello; y cheche = pappagallo en Patagonia; gagia (elefante) en las Molucas.

Hay que destacar el registro puntual de las variedades de la rica fauna ictiológica del Pacífico: al pesce = isam yssida; a un pesce tutto dipinto = panap sapan; a un altro rosso = timuan; a un certo altro = pilax; a un altro = emalvan.

4.6. No siempre fue fácil el contacto con las tribus indígenas. Nada sabemos de las denominaciones que las armas de combate tenían entre los pobladores de Verzin, pero una vez en el Pacífico Pigafetta, por su condición de soldado, les dedica un amplio espacio en sus glosarios. Las armas son las esperadas: arco, flecha, escudo, daga, puñal, lanza, cerbatana. Junto a sus denominaciones, el viajero italiano registra el nombre de los indumentos que los guerreros filipinos utilizan para la lucha: $A$ le vesti imbottite per combatter $=$ baluti. 
4.7. El interés que el autor de la relación del viaje muestra hacia la vida cotidiana de los indígenas queda reflejado en su relación: la red de algodón, o amache, en la que duermen los nativos de Verzin; las pequeñas barcas de madera que éstos utilizan para navegar (canoe); las alfombras en las que duermen los filipinos, o las trenzadas con hojas de palmera; las artes de pescar y las embarcaciones en las que se navega por el Pacífico (entre ellas el sanpan); los instrumentos musicales y de percusión (aghon).

4.8. La curiosidad etnológica de Pigafetta se demuestra no sólo en su interés por todo lo que constituye la vida cotidiana del indígena, sino también por los rasgos más sobresalientes de la espiritualidad de las tribus y no sólo en la etapa final del viaje, cuando más desarrollada es su conciencia lingüística. Así en Patagonia registra los nombres de lo que denomina el diavolo grande $=$ Setebos y li piccoli $=$ Cheleule; en Filipinas al suo Iddio $=$ $A b b a$; y en las Molucas, latitud tocada por el islamismo, al suo dio $=$ Allà, alle sue meschite $=$ mischit y a li sui prete = maulana catip mudir. Al margen de la religión oficial, confluyen en su paso por las Molucas elementos legendarios como el bolon dinata o pájaro del paraíso.

4.9. El cuarto y último inventario de Pigafetta no es sólo léxico, sino que incluye oraciones de significación completa que nos permiten asomarnos a la vida cotidiana del expedicionario: Siediti gentiluomo, Siediti uomo da bene, Guardami, Non mi guardare, Signori, bon prò vifaccia, Già ho mangiato, Uomo, levati di li; Oh come puzza!; Che volete?; Che mandate?; Quanti linguaggi sai?; Dove sta colui?; Come stai?; Questo uomo è un poltrone; Uomo, vien quil!

5. Hemos querido pulsar en el relato de Antonio Pigafetta la conciencia lingüística del hombre occidental de principios del siglo XVI, que se enfrenta a la diversidad de un nuevo continente y de unas tierras desconocidas al navegante europeo.

La lectura de las entradas de los inventarios léxicos de Pigafetta nos ha permitido comprobar una creciente curiosidad lingüística que, a medida que avanza el viaje, deja de ser meramente funcional para integrar aspectos culturales característicos de la diversidad de estos pueblos.

\section{Povzetek}

\section{GLOSARJI JEZIKOV OB TIHEM OCEANU. ANTONIO PIGAFETTA (1519-1522)}

Italijanski pomorščak Antonio Pigafetta, doma iz Vicenze v Benečji, je spremljal Portugalca Magalhãesa na njegovem potovanju okoli sveta. Predvsem iz nuje, pa morda tudi iz nekega zanimanja za jezik si je Pigafetta v Patagoniji, na Moluških otokih in na Filipinih zapisoval besede domorodcev. $\mathrm{Za}$ rabo posadke je sestavil majhen italijansko-moluški slovar. Ta je moral biti zlasti dragocen, ko je Magalhães padel (1521) in je domorodec, ki je dotlej deloval kot prevajalec, druščino pomorščakov zapustil. Ta je bila potlej navezana samo na svoje skromno poznavanje jezika domorodcev. Najbrž so zato prevedene iz italijanščine ne le posamezne besede, ampak fraze in celi stavki. 